\title{
Mitochondrial mutations associated with cardiac angina
}

\author{
Margarita A. Sazonova ${ }^{1,2}$, Anastasia I. Ryzhkova1, Vasily V. Sinyov², Marina D. Sazonova1, Nadezhda N. \\ Nikitina $^{2}$, Tatiana P. Shkurat ${ }^{3}$, Igor A. Sobenin ${ }^{1,2}$, Alexander N. Orekhov ${ }^{1,4}$ \\ 'Laboratory of Angiopathology, Institute of General Pathology and Pathophysiology, Moscow 125315, Russian Federation. \\ ${ }^{2}$ Laboratory of Medical Genetics, National Medical Research Center of Cardiology, Moscow 121552, Russian Federation. \\ ${ }^{3}$ Department of Genetics, Southern Federal University, Rostov-on-Don 344006, Russian Federation. \\ ${ }^{4}$ Institute for Atherosclerosis Research, Skolkovo Innovation Centre, Skolkovo, Moscow 121609, Russian Federation.
}

Correspondence to: Dr. Margarita A. Sazonova, Laboratory of Angiopathology, Institute of General Pathology and Pathophysiology, 8 Baltiyskaya Str., Moscow 125315, Russian Federation. E-mail: margaritaasazonova@gmail.com

How to cite this article: Sazonova MA, Ryzhkova AI, Sinyov VV, Sazonova MD, Nikitina NN, Shkurat TP, Sobenin IA, Orekhov AN. Mitochondrial mutations associated with cardiac angina. Vesse/ P/us 2019;3:8. http://dx.doi.org/10.20517/2574-1209.2019.01

Received:1 Dec 2018 First Decision: 18 Dec 2018 Revised: 19 Jan 2019 Accepted: 20 Jan 2019 Published: 19 Mar 2019

Science Editor: Alexander N. Orekhov Copy Editor: Cai-Hong Wang Production Editor: Huan-Liang Wu

\begin{abstract}
Aim: Cardiac angina is a disease in which discomfort or retrosternal pain may occur. Atherosclerosis of coronary arteries is one of the main risk factors for cardiac angina. The aim of the investigation was to analyze the association of 11 mitochondrial genome mutations with cardiac angina. In our preliminary studies an association of these mutations with atherosclerosis, a risk factor for cardiac angina, was found.
\end{abstract}

Methods: We used samples of white blood cells collected from 192 patients with cardiac angina and 201 conventionally healthy study participants. DNA from blood leukocyte samples was isolated using a phenol-chloroform method. DNA amplicons containing the investigated regions of 11 mitochondrial genome mutations ( $m .12315 \mathrm{G}>\mathrm{A}, \mathrm{m} .652 \mathrm{delG}$, m.5178C >A, m.14459G >A, m.3336T>C, 652insG, m.3256C>T, m.1555A>G, m.15059G>A, m.13513G>A, m.14846G>A) were pyrosequenced. The heteroplasmy level of mitochondrial DNA ( $m$ tDNA) mutations was analyzed using a method developed by our laboratory on the basis of pyrosequencing technology.

Results: According to the obtained data, three mitochondrial mutations of human genome correlated with cardiac angina. A positive correlation was observed for mutation $\mathrm{m} .14459 \mathrm{G}>\mathrm{A}(P \leq 0.05)$. One single nucleotide substitution $\mathrm{m} .5178 \mathrm{C}>\mathrm{A}$ $(P \leq 0.1)$ had a trend for positive correlation. A negative correlation for mutation m.15059G $>$ A with cardiac angina $(P \leq$ 0.05) was found. 
Conclusion: MtDNA mutations m.14459G $>$ A and m.5178C >A can be used for evaluation the predisposition of individuals to atherosclerotic lesions. At the same time, mitochondrial genome mutation m.15059G $>$ A may be used for gene therapy of atherosclerosis.

Keywords: Cardiac angina, gene, mutation, heteroplasmy level, mitochondrial genome, molecular cellular models

\section{INTRODUCTION}

Cardiac angina is a disease in which discomfort or retrosternal pain may occur. Discomfort is felt by patients as pressure or retrosternal burning. Pain often occurs during physical exertion, excessive food ingestion, stress, being in cold air or with a sharp increase in blood pressure ${ }^{[1-5]}$. Cardiac angina is supposed to be caused by narrowing of the arterial lumen up to $50 \%-75 \%$. As a result, there is a discrepancy between the blood flow to the heart and its need for blood. In this case, acute insufficiency of blood supply to the heart happens. The redox processes in the heart muscle become disrupted ${ }^{[2-6]}$. An excessive accumulation of insufficiently oxidized metabolic products (lactic, pyruvic, carbonic and phosphoric acids) and other metabolites occurs. Cardiac angina occurs most often in men over 40, and in women over 50 years. The prevalence of cardiac angina increases with age. For example, in patients who were older than 65 years, the frequency of occurrence of cardiac angina reached 10\%-20\%. One of the main risk factors for cardiac angina is a atherosclerosis of coronary arteries ${ }^{[2-6]}$. Other risk factors for cardiac angina include hypertension, diabetes mellitus, obesity, smoking; stress, hypodynamia, infectious diseases, allergic lesions and genetic mutations $s^{[7-12]}$.

Molecular genetic markers for cardiac angina could help identification of predisposition to the disease much earlier than clinical methods for examining patients. At the present time, such studies are mainly devoted to polymorphisms of the genes in nuclear genome.

Our research group found a number of mitochondrial genome mutations associated with cardiac angina. It should be noted that in the study we investigated those mitochondrial mutations for which, in our preliminary studies, we detected an association with atherosclerosis ${ }^{[13-17]}$. Since atherosclerosis is a risk factor for cardiac angina, we decided to investigate whether these mutations are linked with cardiac angina.

It should be noted that during the investigation of the mitochondrial genome mutations, the level of heteroplasmy is determined. The ratio of the number of mutant mitochondrial DNA (mtDNA) copies in a sample to the total number of mtDNA copies is estimated ${ }^{[13-17]}$. This is the difference between quantitative analysis of mutations in the mitochondrial genome and the analysis of nuclear mutations. In the quantitative analysis of nuclear genome mutations, the number of homozygotes in which both alleles are either mutant or normal. The number of heterozygotes is detected too. Afterwards the mutation frequency in the investigated sample is estimated ${ }^{[18,19]}$.

The level of heteroplasmy in mitochondrial genome mutations was measured using a quantitative method developed in our laboratory ${ }^{[14,17,20]}$. This method is based on the pyrosequencing technology ${ }^{[21,22]}$. Short DNA fragments (6-10 bp), containing the area of mutation were investigated. Such a small length of the studied DNA fragments significantly reduces the number of errors during sequencing.

\section{METHODS}

We used samples of white blood cells collected from 192 patients with cardiac angina and 201 conventionally healthy study participants. These individuals were examined in Moscow State University clinic. In order to 
Table 1. The size of DNA amplicons and primers for PCR

\begin{tabular}{|c|c|c|}
\hline Mutation & Primers & Size of DNA amplicons \\
\hline $\mathrm{m} .12315 \mathrm{G}>\mathrm{A}$ & $\begin{array}{l}\text { F: bio-CTCATGCCCCCATGTCTAA(12230-12249) } \\
\text { R: TTACTTTTATTTGGAGTTGCAC(12337-12317) }\end{array}$ & $108 \mathrm{bp}$ \\
\hline m.652delG & $\begin{array}{l}\text { F: TAGACGGGCTCACATCAC(621-638) } \\
\text { R: bio-GGGGTATCTAATCCCAGTTTGGGT(1087-1064) }\end{array}$ & 467 bp \\
\hline m.3336T $>C$ & $\begin{array}{l}\text { F: bio-AGGACAAGAGAAATAAGGCC (3129-3149) } \\
\text { R: ACGTTGGGGCCTTTGCGTAG(3422-3403) }\end{array}$ & 294 bp \\
\hline m.14459G $>A$ & $\begin{array}{l}\text { F: CAGCTTCCTACACTATTAAAGT(14303-14334) } \\
\text { R: bio-GTTTTTTTAATTTATTTAGGGGG(14511-14489) }\end{array}$ & $209 \mathrm{bp}$ \\
\hline $\mathrm{m} .5178 \mathrm{C}>\mathrm{A}$ & $\begin{array}{l}\text { F: bio-GCAGTTGAGGTGGATTAAAC(4963-4982) } \\
\text { R: GGAGTAGATTAGGCGTAGGTAG(5366-5345) }\end{array}$ & $383 b p$ \\
\hline m.13513G >A & $\begin{array}{l}\text { F: CCTCACAGGTTTCTACTCCAAA(13491-13512) } \\
\text { R: bio-AAGTCCTAGGAAAGTGACAGCGAGG(13825-13806) }\end{array}$ & $335 \mathrm{bp}$ \\
\hline m.652insG & $\begin{array}{l}\text { F: TAGACGGGCTCACATCAC(621-638) } \\
\text { R: bio-GGGGTATCTAATCCCAGTTTGGGT(1087-1064) }\end{array}$ & $467 \mathrm{bp}$ \\
\hline m.3256C $>T$ & $\begin{array}{l}\text { F: bio-AGGACAAGAGAAATAAGGCC(3129-3149) } \\
\text { R: ACGTTGGGGCCTTTGCGTAG(3422-3403) }\end{array}$ & 294 bp \\
\hline m.15059G >A & $\begin{array}{l}\text { F: bio-CATTATTCTCGCACGGACT(14671-14689) } \\
\text { R: GCTATAGTTGCAAGCAGGAG(15120-15100) }\end{array}$ & $450 \mathrm{bp}$ \\
\hline m.1555A>G & $\begin{array}{l}\text { F: TAGGTCAAGGTGTAGCCCATGAGGTGGCAA(1326-1355) } \\
\text { R: bio-GTAAGGTGGAGTGGGTTTGGG(1704-1684) }\end{array}$ & $379 \mathrm{bp}$ \\
\hline $\mathrm{m} .14846 \mathrm{G}>\mathrm{A}$ & $\begin{array}{l}\text { F: bio-CATTATTCTCGCACGGACT(14671-14689) } \\
\text { R: GCTATAGTTGCAAGCAGGAG(15120-15100) }\end{array}$ & $450 \mathrm{bp}$ \\
\hline
\end{tabular}

bp: base pairs

compare the samples of patients with cardiac angina and conventionally healthy study participants more correctly, the samples were composed so that they did not have significant differences in age and sex.

The work was conducted in complance with the Declaration of Helsinki. The study protocol has been accepted by Ethics Community of National Medical Research Center of Cardiology, and all subjects signed an informed consent for inclusion in the research.

DNA from blood leukocyte samples was isolated using a phenol-chloroform method ${ }^{[13,14,23-25]}$. DNA amplicons containing the investigated regions of 11 mitochondrial genome mutations (m.12315G $>A$, m.652delG, m.5178C >A, m.14459G $>$ A, m.3336 T $>$ C, 652insG, m.3256C $>\mathrm{T}, \mathrm{m} .1555 \mathrm{~A}>\mathrm{G}, \mathrm{m} .15059 \mathrm{G}>\mathrm{A}$, $\mathrm{m} .13513 \mathrm{G}>\mathrm{A}, \mathrm{m} .14846 \mathrm{G}>\mathrm{A}$ ) were pyrosequenced. The heteroplasmy level of mtDNA mutations was analyzed using a method developed by our laboratory.

The size of DNA amplicons and primers for PCR are listed in Table $1^{[13-16,20]}$.

In order to be able to perform pyrosequencing of DNA amplicons, one of the primers for PCR was biotinylated.

The total volume of PCR reaction mixtures for each sample was $30 \mathrm{~mL}$. The composition of the reaction mixture for $\mathrm{PCR}^{[13-16,20]}$ : 0.4-0.6 mg mitochondrial DNA, $0.3 \mathrm{pmol} / \mathrm{L}$ of each primer, $200 \mathrm{mmol} / \mathrm{L}$ of each deoxyribonucleotriphosphate, $16.6 \mathrm{mmol} / \mathrm{L}\left(\mathrm{NH}_{4}\right)_{2} \mathrm{SO}_{4}, \mathrm{MgCl}_{2}(1.5 \mathrm{mmol} / \mathrm{L}$ for mutations $\mathrm{m} .14846 \mathrm{G}>\mathrm{A}$, $\mathrm{m} .15059 \mathrm{G}>\mathrm{A}$ and $\mathrm{m} .14459 \mathrm{G}>\mathrm{A} ; 2.5 \mathrm{mmol} / \mathrm{L}$ for the rest of investigated mutations), $67 \mathrm{mmol} / \mathrm{L}$ tris- $\mathrm{HCl}(\mathrm{pH}$ 8.8), and 3 units of Taq-polymerase.

In PCR, the following annealing temperature was used for the primers ${ }^{[13-16,20]}$ :

1. For mutations m.3336 T>C, m.14846G>A, m.13513G >A, m.15059G $>$ A and $\mathrm{m} .3256 \mathrm{C}>\mathrm{T}-55^{\circ} \mathrm{C}$;

2. For mutations $\mathrm{m} .5178 \mathrm{C}>\mathrm{A}, \mathrm{m} .652 \mathrm{delG}$ and $\mathrm{m} .652 \mathrm{ins} \mathrm{G}-60^{\circ} \mathrm{C}$;

3. For mutations $\mathrm{m} .12315 \mathrm{G}>\mathrm{A}, \mathrm{m} .14459 \mathrm{G}>\mathrm{A}$ and $\mathrm{m} .1555 \mathrm{~A}>\mathrm{G}-50^{\circ} \mathrm{C}$. 
Table 2. Primers for pyrosequencing

\begin{tabular}{|c|c|}
\hline Mutation & Primer \\
\hline m.12315G>A & TTTGGAGTTGCAC(12328-12316) \\
\hline m.652delG & CCCATAAACAAATA(639-651) \\
\hline m.3336T $>C$ & TGCGATTAGAATGGGTAC(3354-3337) \\
\hline m.14459G>A & GATACTCCTCAATAGCCA(14439-14456) \\
\hline m. $5178 \mathrm{C}>\mathrm{A}$ & ATTAAGGGTGTTAGTCATGT(5200-5181) \\
\hline $\mathrm{m} .13513 \mathrm{G}>\mathrm{A}$ & AGGTTTCTACTCCAA(13497-13511) \\
\hline m.652insG & CCCATAAACAAATA(639-651) \\
\hline m.3256C>T & AAGAAGAGGAATTGA(3300-3286) \\
\hline$m .15059 G>A$ & TTTCTGAGTAGAGAAATGAT(15080-15061) \\
\hline m.1555A>G & ACGCATTTATATAGAGGA(1537-1554) \\
\hline m.14846G >A & GCGCCAAGGAGTGA(14861-14848) \\
\hline
\end{tabular}

PCR was conducted using "PTC DNA Engine 200"[13-16,20].

The DNA amplicons were analyzed on automated pyrosequencing device PSQTMHS96MA (Biotage, Sweden $)^{[10,11]}$. Primers for pyrosequencing are listed in Table $2^{[13-16,20]}$.

For statistical analysis of the obtained results software package SPSS 22.0 was used ${ }^{[26]}$. Bootstrap analysis was also conducted. Correlation was considered statistically significant at the level of $P \leq 0.05$. The results at the significance level of $P \leq 0.1$ were considered to show a tendency to statistical significance.

\section{RESULTS}

The age characteristics for study participants are presented in Table 3. The age of conventionally healthy participants ranged from 51 to 73 years. In the meantime, the age of patients with cardiac angina ranged from 52 to 76 years. The average age of conventionally healthy study participants was 2 years less than the age of patients with cardiac angina. This age difference between samples of patients with cardiac angina and conventionally healthy participants was not statistically significant.

Demographic characteristics for study participants are presented in Table 4. The data in Table 4 is presented as an average value with indicating the standard deviation (in parentheses).

According to Table 4, statistically significant differences by clinical and anthropometric characteristics between samples of patients with cardiac angina and conventionally healthy study participants were not found.

The aim of the investigation was to analyze the association of 11 mitochondrial genome mutations with cardiac angina: $\mathrm{m} .12315 \mathrm{G}>\mathrm{A}, \mathrm{m} .652 \mathrm{delG}, \mathrm{m} .5178 \mathrm{C}>\mathrm{A}, \mathrm{m} .14459 \mathrm{G}>\mathrm{A}, \mathrm{m} .3336 \mathrm{~T}>\mathrm{C}, 652 \mathrm{ins} \mathrm{G}, \mathrm{m} .3256 \mathrm{C}>\mathrm{T}$, m.1555A $>$ G, m.15059G $>A, m .13513 \mathrm{G}>\mathrm{A}, \mathrm{m} .14846 \mathrm{G}>\mathrm{A}$. In our preliminary studies, an association of these mutations with atherosclerosis, a risk factor for cardiac angina, was identified. Therefore, we decided to investigate whether these mutations have a link with cardiac angina.

Statistical analysis of the link of these mitochondrial genome mutations with cardiac angina is presented in Table 5.

As illustrated in Table 5, three mitochondrial mutations of human genome correlated with cardiac angina. A positive correlation was observed for mutation m.14459G $>$ A $(P \leq 0.05)$. One single nucleotide substitution m.5178C $>$ A $(P \leq 0.1)$ had a trend for positive correlation with this disease. We suppose that in case of 
Table 3. Age characteristics of the study participants

\begin{tabular}{|c|c|c|c|c|}
\hline \multirow[b]{2}{*}{ Investigated individuals } & \multicolumn{3}{|c|}{ Age } & \multirow[b]{2}{*}{ Standard deviation } \\
\hline & $\begin{array}{c}\text { Minimum, } \\
\text { (years) }\end{array}$ & $\begin{array}{c}\text { Mean, } \\
\text { (years) }\end{array}$ & $\begin{array}{c}\text { Maximum, } \\
\text { (years) }\end{array}$ & \\
\hline Conventionally healthy study participants & 51 & 62 & 73 & 8.3 \\
\hline Patients with cardiac angina & 52 & 64 & 76 & 8.1 \\
\hline
\end{tabular}

Table 4. Demographic characteristics of the study participants

\begin{tabular}{|c|c|c|c|}
\hline Parameter & Conventionally healthy study participants & Patients with cardiac angina & Significance of differences \\
\hline Sex, M/F & $91: 101$ & 103:98 & 0.146 \\
\hline Age, years & $62(8.3)$ & $64(8.1)$ & 0.111 \\
\hline Body mass index, $\mathrm{kg} / \mathrm{m}^{2}$ & $24.8(5.9)$ & $26.5(6.3)$ & 0.152 \\
\hline Systolic blood pressure, $\mathrm{mmHg}$ & $123(16)$ & $147(26)$ & 0.214 \\
\hline Diastolic blood pressure, $\mathrm{mmHg}$ & $82(18)$ & $91(23)$ & 0.319 \\
\hline Smoking, \% & 29 & 38 & 0.167 \\
\hline
\end{tabular}

expansion of the sample, positive correlation m.5178C $>$ A with cardiac angina will become significant. For mutation $\mathrm{m} .15059 \mathrm{G}>\mathrm{A}$ a significant negative correlation with this disease was found $(P \leq 0.05)$.

\section{DISCUSSION}

From the data obtained in this study, it can be concluded that mitochondrial genome mutations m.14459G $>\mathrm{A}$ and $\mathrm{m} \cdot 5178 \mathrm{C}>\mathrm{A}$ are risk factors for the occurrence and development of cardiac angina. Meanwhile, the mutation $\mathrm{m} .15059 \mathrm{G}>\mathrm{A}$ had a protective effect in this disease.

The detected mutations were localised in the coding region of mtDNA. Single nucleotide replacements m.14459G $>A$ and $m .5178 \mathrm{C}>\mathrm{A}$ were localised in the genes of the second and sixth subunits of NADH dehydrogenase. We assume that the defects of this mitochondrial respiratory chain enzyme is a trigger of pathological mechanisms in the human body, as a result of which ATP deficiency occurs. Energy deficit, in turn, leads to the emergence and development of cardiac angina.

At the same time, mtDNA mutation $\mathrm{m} .15059 \mathrm{G}>\mathrm{A}$ is localised in the cytochrome B gene. Perhaps this mutation is involved in molecular cell processes which protect a person from the occurrence of cardiac angina.

Mitochondrial genome mutations $\mathrm{m} .14459 \mathrm{G}>\mathrm{A}$ and $\mathrm{m} .5178 \mathrm{C}>\mathrm{A}$ may be candidates for the creation of molecular cell models in the development of drug therapy for patients with cardiac angina. Mutation m.15059G>A can be used for creating gene therapy approaches to this disease.

Molecular genetic markers for cardiac angina could help the identification of predisposition to the disease much earlier than clinical methods for examining patients. At the present time, such studies are mainly devoted to polymorphisms of nuclear genome genes. Studies of mitochondrial genome mutations in cardiac angina are practically absent. Therefore, analysis of the association of mtDNA mutations with cardiac angina, conducted by our research group, is very relevant.

In conclusion, according to the obtained data, three mitochondrial mutations of human genome correlated with cardiac angina. A positive correlation was observed for mutation $\mathrm{m} .14459 \mathrm{G}>\mathrm{A}(P \leq 0.05)$. One single nucleotide substitution $\mathrm{m} .5178 \mathrm{C}>\mathrm{A}(P \leq 0.1)$ had a trend for positive correlation. A negative correlation for mutation $\mathrm{m} .15059 \mathrm{G}>\mathrm{A}$ with cardiac angina $(P \leq 0.05)$ was found. 
Table 5. Spearman correlation analysis of 11 mitochondrial genome mutations with cardiac angina

\begin{tabular}{lcc}
\hline Mutation & Correlation coefficient & Significance \\
\hline m.12315G $>$ A & 0.079 & 0.121 \\
m.652delG & 0.061 & 0.224 \\
m.3336T>C & 0.047 & 0.342 \\
m.14459G $>$ A & 0.116 & $0.034^{\star \star}$ \\
m.5178C $>$ A & 0.092 & $0.068^{\star}$ \\
m.13513G $>A$ & -0.075 & 0.129 \\
m.652insG & -0.078 & 0.124 \\
m.3256C>T & 0.069 & 0.218 \\
m.15059G $>A$ & -0.122 & $0.036^{\star \star}$ \\
m.1555A>G & -0.065 & 0.217 \\
$m .14846 G>A$ & -0.068 & 0.222 \\
\hline & $\star \star P \leq 0.05 ; * P \leq 0.1$ &
\end{tabular}

MtDNA mutations m.14459G $>$ A and $\mathrm{m} .5178 \mathrm{C}>\mathrm{A}$ can be used for evaluation the predisposition of individuals to atherosclerotic lesions. At the same time, mitochondrial genome mutation $\mathrm{m} .15059 \mathrm{G}>\mathrm{A}$ may be used for gene therapy of atherosclerosis.

\section{DECLARATIONS}

\section{Authors' contributions}

Conception, design and statistical analysis: Sazonova MA

Pyrosequencing of PCR fragments: Sazonova MA, Sinyov VV

PCR: Ryzhkova AI, Shkurat TP

DNA extraction: Sazonova MD, Nikitina NN

Administrative and material support: Sobenin IA, Orekhov AN

\section{Availability of data and materials}

The data were strictly obtained from medical records according to the privacy policy and ethics code of our institute.

\section{Financial support and sponsorship}

This work was supported by the Russian Foundation for Basic Research (19-015-00479).

\section{Conflicts of interest}

All authors declared that there are no conflicts of interest.

\section{Ethical approval and consent to participate}

The study was carried out in accordance with the Declaration of Helsinki. The study protocol was inspected and approved by the Ethics Committee of the Institute of General Pathology and Pathophysiology. Each study participant has signed a written informed consent to participate in this investigation.

\section{Consent for publication}

Not applicable.

\section{Copyright}

(c) The Author(s) 2019.

\section{REFERENCES}

1. Hoffmann U, Massaro JM, D’Agostino RB Sr, Kathiresan S, Fox CS, et al. Cardiovascular event prediction and risk reclassification by coronary, aortic, and valvular calcification in the Framingham heart study. J Am Heart Assoc 2016;5:e03144. 
2. Fraker TD Jr, Fihn SD; 2002 Chronic Stable Angina Writing Committee; American College of Cardiology; American Heart Association, et al. 2007 chronic angina focused update of the ACC/AHA 2002 guidelines for the management of patients with chronic stable angina: a report of the American College of Cardiology/American Heart Association Task Force on Practice Guidelines Writing Group to develop the focused update of the 2002 guidelines for the management of patients with chronic stable angina. J Am Coll Cardiol 2007;50:2264-74.

3. Lazari J, Money-Kyrle A, Wakerley BR. Cardiac cephalalgia: severe, non-exertional headache presenting as unstable angina. Pract Neurol 2018; doi: 10.1136/practneurol-2018-002045.

4. Fineschi M, D'Ascenzi F, Sirbu V, Mondillo S, Pierli C. Diagnosis and management of a patient with recurrent variant angina and history of percutaneous coronary intervention: vasospasm and percutaneous coronary intervention. J Cardiovasc Med (Hagerstown) 2018;19:31-3.

5. Suhrs HE, Kristensen AM, Rask AB, Michelsen MM, Frestad D, et al. Coronary microvascular dysfunction is not associated with a history of reproductive risk factors in women with angina pectoris-An iPOWER substudy. Maturitas 2018;107:110-15.

6. Guan XQ, Xue YJ, Wang J, Ma J, Li YC, et al. Low bone mineral density is associated with global coronary atherosclerotic plaque burden in stable angina patients. Clin Interv Aging 2018;13:1475-83.

7. Abbasi M, Neishaboury M, Koohpayehzadeh J, Etemad K, Meysamie A, et al. National prevalence of self-reported coronary heart disease and chronic stable angina pectoris: factor analysis of the underlying cardiometabolic risk factors in the SuRFNCD-2011. Glob Heart 2018;13:73-82.e1.

8. Thokala P, Kruger J, Brennan A, Basarir H, Duenas A, et al. Assessing the cost-effectiveness of type 1 diabetes interventions: the Sheffield type 1 diabetes policy model. Diabet Med 2014;31:477-86.

9. Haberka M, Mizia-Stec K, Lasota B, Kyrcz-Krzemień S, Gąsior Z. Obesity and antiplatelet effects of acetylsalicylic acid and clopidogrel in patients with stable angina pectoris after percutaneous coronary intervention. Pol Arch Med Wewn 2015;125:620-30.

10. Ponikowski P, Voors AA, Anker SD, Bueno H, Cleland JGF, et al. 2016 ESC guidelines for the diagnosis and treatment of acute and chronic heart failure: the task force for the diagnosis and treatment of acute and chronic heart failure of the European Society of Cardiology (ESC) Developed with the special contribution of the Heart Failure Association (HFA) of the ESC. Eur Heart J 2016;37:2129-200.

11. Buchanan DM, Arnold SV, Gosch KL, Jones PG, Longmore LS, et al. Association of smoking status with angina and health-related quality of life after acute myocardial infarction. Circ Cardiovasc Qual Outcomes 2015;8:493-500.

12. Gaibazzi N. Stress echocardiography: need to optimize its appropriate use in suspected angina and a review of available additional tools for its clinical application in 2018: first do no harm! second do it at the highest possible accuracy. J Cardiovasc Echogr 2018;28:154-9.

13. Sazonova MA. Association of mitochondrial genome mutations with lipofibrous plaques in human aortic intima. Patol Fiziol Eksp Ter 2015;59:17-28. (in Russian)

14. Sazonova M, Budnikov E, Khasanova Z, Sobenin I, Postnov A, et al. Studies of the human aortic intima by a direct quantitative assay of mutant alleles in the mitochondrial genome. Atherosclerosis 2009;204:184-90.

15. Sazonova MA, Sinyov VV, Ryzhkova AI, Galitsyna EV, Khasanova ZB, et al. Role of mitochondrial genome mutations in pathogenesis of carotid atherosclerosis. Oxid Med Cell Longev 2017; 2017:6934394.

16. Sazonova MA, Sinyov VV, Barinova VA, Ryzhkova AI, Zhelankin AV, et al. Mosaicism of mitochondrial genetic variation in atherosclerotic lesions of the human aorta. Biomed Res Int 2015;2015:825468.

17. Sazonova MA, Postnov AIu, Orekhov AN, Sobenin IA. A new method of quantitative estimation of mutant allele in mitochondrial genome. Patol Fiziol Eksp Ter 2011;4:81-4. (in Russian)

18. Zbuk K, Xie C, Young R, Heydarpour M, Pare G, et al. BRCA2 variants and cardiovascular disease in a multi-ethnic study. BMC Med Genet 2012;13:56

19. Amosenko FA, Trubnikova IS, Zakhar'ev VM, Bannikov VM, Sazonova MA, et al. TUB9 polymorphism in the CFTR gene of cystic fibrosis patients, carriers, and healthy donors from the Moscow region. SSCP and restriction analyses. Genetika 1997;33:257-61. (in Russian)

20. Sazonova MA, Ryzhkova AI, Sinyov VV, Galitsyna EV, Orekhova VA, et al. New markers of atherosclerosis: a threshold level of heteroplasmy in mtDNA mutations. Vessel Plus 2017;1:182-91.

21. Goji N, Mathews A, Huszczynski G, Laing CR, Gannon VP, et al. A new pyrosequencing assay for rapid detection and genotyping of Shiga toxin, intimin and O157-specific rfbE genes of Escherichia coli. J Microbiol Methods 2015;109:167-79.

22. Alderborn A, Kristofferson A, Hammerling U. Determination of single-nucleotide polymorphisms by real-time pyrophosphate DNA sequencing. Genome Res 2000;10:1249-58.

23. Amosenko FA, Sazonova MA, Kapranov NI, Trubnikova IS, Kalinin VN. Analysis of various polymorphic markers of the CFTR gene in cystic fibrosis patients and healthy donors from the Moscow region. Russ J Genet 1995;31:457-9.

24. Sazonova MA, Amosenko FA, Kapranov NI, Kalinin VN. Molecular genetic analysis of TUB18 and TUB20 intragenic polymorphism and various mutations of the CFTR gene in the Moscow region. Genetika 1997;33:1303-7. (in Russian)

25. Bilovol O. Predictors of hormonal and metabolic disorders of arterial hypertension and type 2 diabetes mellitus comorbidity. Vessel Plus 2017;1:22-8.

26. IBM SPSS software. Available from: https://www.ibm.com/analytics/us/en/technology/spss. [Last accessed on 11 Mar 2019]. 